mental health problems among the homeless (e.g. Weller, Tobiansky \& Hollander, 1989). This contrasts with the rigorous epidemiological studies carried out in America (Tessler \& Dennis, 1989). Commendably the White Paper makes it clear that DHAs will be expected to assess the needs of its local population. However such assessments, if they are to be of any value, are likely to be expensive and the funding of such exercises remains obscure.

The Government has initiated major changes in the way services within the NHS are provided. However, the same changes have been applied across all specialties and districts without taking into account the significant differences that exist between them. It is for clinicians to provide accurate data to describe these differences in order to justify claims to resources. It is only by doing so that the 'artist's impression' will gain sufficient detail to become a useful blueprint from which adequate and relevant services can be planned.

\section{References}

Department of Health (1989a) Working for Patients. London: HMSO.

- (1989b) Working Paper 11, Annex 12. London: HMSO.

- (1989c) Caring for People: Community Care in the Next Decade and Beyond. London: HMSO.

Fisher, N., TurNer, S. \& PUGH, R. (1990) Homeless and mentally ill. Lancet, $i, 914-915$.

PECK, E. (1989) Working for psychiatric patients? Mental health services and the White Paper. Psychiatric Bulletin, $13,407-408$.

Royal College of Psychiatrists (1988) Caring for a Community. 1. The model mental health service. London: Royal College of Psychiatrists.

- (1989) Comments of the Royal College of Psychiatrists on the NHS White Paper: Working for Patients. Psychiatric Bulletin, 13, 385-389.

TESSLER, R. \& DENNIS, D. (1989) A Synthesis of NIMHfunded Research Concerning Persons who are Mentally Ill. Washington DC: National Institute of Mental Health.

Weller, M., TObiansky, R. \& Hollander, D. (1989) Destitution at the festive season. Lancet, $i, 220$.

\title{
Choosing trust status: should we trust it?
}

\author{
D. H. Dick, Consultant Psychiatrist, Herrison Hospital, Dorchester, Dorset DT2 9RL
}

The proposals outlined in the White Paper, Caring for People, are now law and were little affected by the wave of protest which greeted them when they were first published. So the time has probably come to see what can be made of them and how they might be turned to advantage, rather than continuing to worry about the politics of whether change was necessary at all.

In the West Dorset Health District, especially within the psychiatric services based at Herrison Hospital, we decided early on that we should explore what opportunities might come from riding the wave of likely change rather than swimming against it. As the National Health Service is in a state of continuous change, there seemed little point in spending much energy in joining the automatic response which any proposal for change provokes. There might be advantages.

There were only five consultants in our adult mental health services so that we were able to come to a firmly shared decision quite quickly. We could begin the exploration of whether or not to choose trust status. It was clear that to retain the status quo would not be an option. We would either become a trust or a directly managed unit. The worst outcome of being directly managed would be to become a subdepartment of a large general hospital unit whose dominating priorities were those of acute medicine. The differences between trust and direct management would not be great. Those that there were would mean a lot to reaching the aims of the developments which we had nurtured for a long time. We wanted to regain control of the process of change in our services which has been steadily leaking away from clinicians, since the arrival of increasingly centralised management decisions, through the adoption of general management. We wanted to be able to set out our own priorities and not remain tangled in other parts of the health service which always seemed to attract more of the health authority's attention. 
We wanted our managers to be loyal to our specialty and not always have to keep an eye on wider corporate demands from the district.

We had pursued a clear policy for many years of using the opportunities of bed reduction and changed practice in the mental hospital to develop really satisfactory community alternatives. Like many others we were losing the chance to benefit from our own savings. We wanted to retain the integrity of that policy which was in danger of being fragmented into locality management and in-patient and 'illness episode' dominated care. There was a wish to return to 'company loyalty' because everyone was fading into dispersed management lines and professional groups. These had responsibility to a spread of disciplines and departments, outside mental health, but little to the common purpose of serving the mentally disordered. Trust status seemed to offer a return of control and a fence round our budget, both for revenue and capital. We would regain the advantage of a managing authority which was dedicated to the interests of the mentally disordered and no-one else.

There were further persuasive arguments which emerged as we began to investigate trust status. Capital development would be through the external financing limit and not subject to regional health authority rationing. We would be developing what we could afford, not what we could beg. We would not be at risk that the district health authority could close down parts of our service because they could be bought more cheaply elsewhere. We would have the ability to hire the staff which we needed for locally sensitive pay. There would be opportunities to devise our own information technology systems and not have them bought for us because they suited the wider district. Service agreements (contracts) would be negotiated by ourselves as service providers and not by a district organisation which would also be purchasing services. These negotiations would define very specific responsibilities and how they might be monitored. Job descriptions would be worked out between the trust and its psychiatrists, not as a wider NHS agreement. Above all there would be separation into discrete organisations, one of which would be describing requirements (the shopping list) and the other would be offering services (the catalogue). We set about writing the catalogue (West Dorset Health Authority, 1990).

So far, the reasoning was about taking advantage of organisational change, but would it be helpful in improving the mental health service for our local community? The health district's theme for mental health for many years has been to develop local domestically based services for the whole range of mental disorder, retaining high quality central services but dispersing what did not need to be central to local communities. We have been shifting our focus of treatment from the primacy of hospitals to responsibility for a territory, from episode medicine to a longitudinal approach and from the single axis of the patient to doctor relationship to issues of stabilisation and the quality of life at home within the family or in a domestic setting, shared with a variety of other agencies. The 'bed' has become much less important than the availability and quality of local treatment, housing and opportunities for social and occupational activity, supported by community psychiatric services. There are already no more long-stay patients from the health district left in our mental hospital; they are all living somewhere else. These are not concepts which fit well with the recent preoccupations of Ministers and senior health service managers. These have been to strengthen institutional efficiency, to have larger cost effective centres to cope with advancing technology, to have more treatments per pound, and to reduce waiting lists for admission to specialist health care. Modern psychiatry seems to be about providing specialist services in other people's environments, not about providing the environment itself. It is 'boutique psychiatry' or as Malcolm Faulk expresses it, 'pebble-dash psychiatry'.

The weight of argument persuaded us to examine seriously the possibility of trust status, as a means of keeping psychiatry in the hands of psychiatrists. The consultants and senior managers spent several days, separated in time, in discussion away from the hospital, usually in congenial surroundings, in a local pub ('the Conference Centre'), arriving at a prospectus to present to the Secretary of State for approval. Although we had a facilitator, this was not an easy process. We were having to devise the structure as well as the content of our proposal. It was not as if we were writing our version of a working model. The ground was unexplored. We were greatly helped by district staff in shaping our ideas. We were very grateful that they took on the burden of preparing innumerable drafts for us to argue over. The outcome, at least, is an agenda for coping with the latest set of rules which we have been sent. We decided to apply for trust status, because it seemed that we would probably be in a better position to meet the changes and challenges of the National Health Service reforms as a trust than as a directly managed unit. We thought that on balance it would be better for our patients. There is no other test.

\section{Reference}

West Dorset Health Authority (1990) Prospectus for West Dorset Mental Health Care Trust. Dorchester, Dorset: West Dorset Health Authority. 